Marquette University

e-Publications@Marquette

$3-2015$

\title{
Parent and Family Outcomes of PEERS: A Social Skills Intervention for Adolescents with Autism Spectrum Disorder
}

Jeffrey S. Karst

Marquette University, jeffrey.karst@marquette.edu

Amy V. Van Hecke

Marquette University, amy.vanhecke@marquette.edu

Audrey M. Carson

Marquette University

Sheryl Jayne Stevens

Marquette University, sheryl.stevens@marquette.edu

Kirsten A. Schohl

Marquette University, Kristen.schohl@marquette.edu

See next page for additional authors

Follow this and additional works at: https://epublications.marquette.edu/psych_fac

Part of the Psychology Commons

\section{Recommended Citation}

Karst, Jeffrey S.; Van Hecke, Amy V.; Carson, Audrey M.; Stevens, Sheryl Jayne; Schohl, Kirsten A.; and Dolan, Bridget, "Parent and Family Outcomes of PEERS: A Social Skills Intervention for Adolescents with Autism Spectrum Disorder" (2015). Psychology Faculty Research and Publications. 158.

https://epublications.marquette.edu/psych_fac/158 


\section{Authors}

Jeffrey S. Karst, Amy V. Van Hecke, Audrey M. Carson, Sheryl Jayne Stevens, Kirsten A. Schohl, and Bridget Dolan

This article is available at e-Publications@Marquette: https://epublications.marquette.edu/psych_fac/158 


\title{
Parent and Family Outcomes of PEERS: A Social Skills Intervention for Adolescents with Autism Spectrum Disorder
}

\author{
Jeffrey S. Karst \\ Department of Psychology, Marquette University, \\ Children's Hospital of Wisconsin, \\ Milwaukee, WI \\ Amy Vaughan Van Hecke \\ Department of Psychology, Marquette University \\ Milwaukee, WI \\ Audrey M. Carson \\ Texas Children's Hospital, \\ Houston TX \\ Department of Psychology, Marquette University \\ Milwaukee, WI \\ Sheryl Stevens \\ Department of Psychology, Marquette University \\ Milwaukee, WI \\ Kirsten Schohl \\ Department of Psychology, Marquette University \\ Milwaukee, WI
}

Journal of Autism and Developmental Disorders, Vol 45, No. 3 (March 2015): pg. 752-765. DOI. This article is (C) Springer and permission has been granted for this version to appear in e-Publications@Marquette. Springer does not grant permission for this article to be further copied/distributed or hosted elsewhere without the express permission from Springer. 
NOT THE PUBLISHED VERSION; this is the author's final, peer-reviewed manuscript. The published version may be accessed by following the link in the citation at the bottom of the page.

\author{
Bridget Dolan \\ Department of Psychology, Marquette University \\ Milwaukee, WI
}

\begin{abstract}
Raising a child with an Autism Spectrum Disorder (ASD) is associated with increased family chaos and parent distress. Successful longterm treatment outcomes are dependent on healthy systemic functioning, but the family impact of treatment is rarely evaluated. The Program for the Education and Enrichment of Relational Skills (PEERS) is a social skills intervention designed for adolescents with high-functioning ASD. This study assessed the impact of PEERS on family chaos, parenting stress, and parenting self-efficacy via a randomized, controlled trial. Results suggested beneficial effects for the experimental group in the domain of family chaos compared to the waitlist control, while parents in the PEERS experimental group also demonstrated increased parenting self-efficacy. These findings highlight adjunctive family system benefits of PEERS intervention and suggest the need for overall better understanding of parent and family outcomes of ASD interventions.
\end{abstract}

Keywords: Autism, Parents, Caregivers, PEERS, Intervention

\title{
Introduction
}

Autism Spectrum Disorder (ASD) is a diagnosis characterized by deficits in social communication and the presence of restricted, repetitive, and stereotyped interests and behaviors (American Psychiatric Association 2013). Individuals with ASD demonstrate mild to severe impairment early in development and continue to experience difficulties throughout the lifespan. The increased rate of ASD diagnoses ( 1 in 68 children: Center for Disease Control and Prevention 2014) has contributed to a high level of demand for effective services. However, there is great variability in therapy options available for children and adolescents with ASD, and marked discrepancy remains among the outcome measures used to determine empirical support for these interventions. The great majority of outcome studies to date have focused directly on the child, ignoring the broader family environmental context and leading to an incomplete picture of the 
benefits and costs of any particular treatment (Karst and Van Hecke 2012). The limited research on family and parent outcomes, which to date has primarily stemmed from evaluation of parent training programs, suggests a number of family and caregiver-level benefits of intervention; including improved family relationships (Rogers 2000; Schertz and Odom 2007), reduced levels of parenting stress and depression (McConachie and Diggle 2007; Roberts and Pickering 2010) and greater parenting self-efficacy (e.g., Sofronoff and Farbotko 2002). It is likely that these positive environmental changes serve to enhance, or at least maintain, gains made by a child or adolescent in treatment.

The Program for the Education and Enrichment of Relationship Skills (PEERS; Laugeson and Frankel 2010) is an empirically supported social skills intervention for adolescents with ASD that includes extensive parent involvement throughout treatment. The PEERS intervention has been offered through this midsized university's autism clinic beginning in the fall of 2010. This paper will review the impact that having a child with an ASD can have on families; followed by a brief review of social skills interventions, including the PEERS program specifically, and review the limited research on parent outcomes of such treatments. Finally, the current investigation will be presented, which sought to determine whether families and caregivers demonstrated benefit from participating in the PEERS intervention.

\section{Impact of ASD on Parents and Families}

The impact of raising a child with ASD is extensive and multifaceted. Families face significant demands on their time due to the many needs of children with ASD, which frequently includes participation in intensive therapy. Further, families are often required to be flexible with their schedule in order to accommodate the diagnosed child's idiosyncratic routines and behavior. In addition, families often deal with significant financial demands secondary to the cost of therapies, necessity of frequent travel for treatment, and limitations on opportunities to work (Lord and Bishop 2010). The extensive commitment required of families raising a child on the autism spectrum often persists throughout the lifespan, as approximately $85 \%$ of individuals with ASD require lifelong family 
assistance in some fashion (Volkmar and Pauls 2003). Raising a child with ASD appears to negatively impact the well-being of parents and families regardless of symptom severity (Ekas et al. 2010; Pottie and Ingram 2008), suggesting that even families of children with "higherfunctioning" ASD are negatively affected.

One of the most salient domains of impact caused by ASD is the increase in chaos, or disorganization and lack of order and routine, in the family system. Increased disorder within the family has been attributed to numerous factors associated with raising a child with ASD, including the persistent time pressures and extensive financial burden described earlier, as well as increased necessity for vigilant parenting that is focused on one child in the family, constant self- and child-advocacy (particularly with regards to education) that takes time away from other family necessities, fewer opportunities to work, and often the presence of one or more therapists in the home (Lord and Bishop 2010; Morrison et al. 2009; Pakenham et al. 2005; Woodgate et al. 2008). Additionally, researchers have found that families of children with ASD are more likely to use maladaptive coping behaviors during times of crisis (Sivberg 2002), exacerbating the disruptive nature of child emotional or behavioral problems. Greater disruption appears to contribute to a general decrease in family quality of life (QOL) in families of children with ASD when compared to the general population (Lee et al. 2008; Mugno et al. 2007; Sivberg 2002).

Increased family chaos can cause reciprocal negative effects on the child with ASD, as higher levels of family chaos are associated with greater risk of child conduct problems (Midouhas et al. 2013). The increased chaos seen in families of children with ASD may also contribute to increased parental conflict and decreased marital satisfaction seen in these families (Brobst et al. 2009; Gau et al. 2011; Harper et al. 2013; Hartley et al. 2011). The presence of emotional strain and relationship difficulties likely make it more difficult for children with ASD to learn appropriate social behaviors, as more maladaptive interactions are modeled by caregivers who are frequently engaged in conflict. An increase in family conflict may also create a barrier to participating in enjoyable and potentially beneficial activities, as families of children with ASD have been found to limit involvement in community activities (Lam et al. 2010). Notably, Kelly et al. (2008) noted that family conflict was predictive of ASD symptom presentation 
and found that negative family relationships influenced ASD symptom manifestation more than positive family interactions. These findings are understandable given the propensity for most children with ASD to perform best in situations with order, structure, and routine. Given this preference, it is not surprising that children of ASD pick up on and are negatively affected by familial chaos and distress.

In addition to systemic disorder within the family, caregivers of children with ASD are affected at the individual level. Parents of children with ASD experience higher levels of parenting stress than parents of typically developing children (e.g., Duarte et al. 2005; Hayes and Watson 2012; Hoffman et al. 2009; Rao and Beidel 2009) as well as parents of children with other developmental disabilities (e.g., Estes et al. 2009, 2012; Schieve et al. 2007, 2011). This is concerning given that high levels of parenting stress are associated with diminished child outcomes over time following intervention (Osborne et al. 2008a, b). Additionally, parents of children with ASD demonstrate decreased confidence in their parenting abilities. This decrease in parenting self-efficacy (PSE) is important to assess given the association between low PSE and increased levels of parenting stress in parents of children with disabilities (Giallo et al. 2011). Sofronoff and Farbotko (2002) noted that increased PSE postintervention was associated with fewer reported child behavior problems, suggesting that increases in PSE provides a direct benefit to the child with ASD.

\section{Social Skills Interventions for ASD}

Given the significant strain associated with raising a child diagnosed with ASD, it is important to understand how specific treatments impact parents and families. The majority of interventions for high-functioning adolescents with ASD focus on addressing social deficits, which are important to address given the negative outcomes associated with ostracism in adolescents with ASD (Sebastian et al. 2009). Such interventions available for pre-teens and teenagers with ASD have demonstrated empirical evidence for improving social deficits (Reichow and Volkmar 2010). Unfortunately, White et al. (2007) noted that many of the gains made during treatment appear to diminish after treatment has concluded. One of the primary factors 
necessary for social skill maintenance is to help children with ASD generalize the skills learned in treatment to broader contexts (Rao et al. 2008). Increased generalization of skills is likely more difficult without systemic changes made during treatment at both the family and parent level. Many of the social skills programs which include higher levels of parental involvement have demonstrated evidence of long-term benefit, including the Program for the Education and Enrichment of Relationship Skills (PEERS; Laugeson et al. 2009).

The PEERS treatment curriculum is a 14-week manualized intervention (Laugeson and Frankel 2010) that was developed as an extension of Children's Friendship Training (CFT; Frankel and Myatt 2003). The PEERS program uses a variety of cognitive-behavioral principles to help enhance the social functioning of adolescents with ASD (see Table 1). Preliminary research on PEERS has identified significant social skills and friendship improvements in adolescents with ASD immediately following intervention and at 14-week follow-up (Laugeson et al. 2011), as well as up to 5 years post-treatment (Mandelberg et al. 2014). Mandelberg et al. noted in their long-term outcome study that parent involvement in this intervention likely plays a large role in the maintenance of treatment gains from PEERS. Specifically, Laugeson and Park (2014) suggested that the "social coaching" (p. 93) role of parents during and after PEERS is imperative for generalizing skills learned during treatment.

Table 1. PEERS sessions and content

\begin{tabular}{ll} 
Session & \multicolumn{1}{c}{ Didactic } \\
1 & Introduction and conversational skills I: trading information \\
2 & Conversational skills II: Two-way conversations \\
3 & Conversational skills III: Electronic communication \\
4 & Choosing appropriate friends \\
5 & Appropriate use of humor \\
6 & Peer entry I: entering a conversation \\
7 & Peer entry II: exiting a conversation \\
8 & Get-togethers \\
9 & Good sportsmanship \\
10 & Rejection 1: teasing and embarrassing feedback \\
11 & Rejection II: bullying and bad reputations \\
12 & Handling disagreements \\
13 & Rumors and gossip \\
14 & Graduation and termination
\end{tabular}

Journal of Autism and Developmental Disorders, Vol 45, No. 3 (March 2015): pg. 752-765. DOI. This article is (C) Springer and permission has been granted for this version to appear in e-Publications@Marquette. Springer does not grant permission for this article to be further copied/distributed or hosted elsewhere without the express permission from Springer. 
NOT THE PUBLISHED VERSION; this is the author's final, peer-reviewed manuscript. The published version may be accessed by following the link in the citation at the bottom of the page.

\section{Summary and Objectives}

Raising a child with ASD is associated with family disruption and parent distress. There appears to be a transactional relationship among the well-being of families and the overall functioning of children with ASD (e.g., Mandell et al. 2011; Osborne et al. 2008a, b; Siller and Sigman 2002). However, comprehensive evaluation of parent and family outcomes is limited in ASD intervention research, and practically non-existent in research of social skills programs. This limitation has led to incomplete understanding of factors associated with positive treatment outcomes, particularly over the long term (Karst and Van Hecke 2012).

Thus, the primary aim of this study was to understand the impact of the PEERS program, which includes extensive family involvement, on family chaos, parenting stress, and parenting selfefficacy. The PEERS program appears likely to reduce household chaos by providing increased structure and order for families, particularly in the domain of their teen's social interactions, via the presentation of rote rules for initiating and maintaining friendships as well as for dealing with negative events. Further, it was expected that PEERS would reduce parenting stress by providing parents education on trouble-shooting their teen's social difficulties (via the PEERS curriculum and providers. It was also expected that the guidelines provided throughout PEERS would help increase parenting self-efficacy by providing parents with concrete methods for addressing problematic situations such as peer ostracism, conflict, teasing, and bullying. Thus, it was predicted that, following 14 weeks of PEERS intervention: (1) Families in the experimental group would demonstrate decreased levels of family chaos compared to those in the waitlist control group, as measured by the Confusion, Hubbub, and Order Scale (CHAOS; Matheny et al. 1995); (2) Parents in the experimental group would demonstrate significantly decreased levels of total parenting stress compared to parents in the waitlist control group, as measured by the Stress Index for Parents of Adolescents (SIPA; Sheras et al. 1998); and (3) Parents in the experimental group would demonstrate significantly increased levels of parenting self-efficacy compared to parents in the waitlist control group, as measured by the parenting self-efficacy subscale of the Parenting Sense of Competence Scale 
NOT THE PUBLISHED VERSION; this is the author's final, peer-reviewed manuscript. The published version may be accessed by following the link in the citation at the bottom of the page.

(PSOC; Gibaud and Wandersman 1978, as cited in Johnston and Mash 1989).

\section{Methods}

\section{Participants}

The study was part of a larger randomized, controlled trial evaluating several domains of PEERS outcomes and was approved through the university Institutional Review Board. The PEERS intervention was offered free of charge to families participating in this study. Incentive for participation limited to a small prize (i.e., approximately 25 dollars in value) provided at the end of PEERS for teens who successfully completed the program.

The final sample for this study consisted of 64 parent-child dyads (32 from both the experimental and waitlist control group; see Fig. 1 for recruitment details). The experimental group included 22 female caregivers and 10 male caregivers along with 26 male adolescents and 6 female adolescents, while the waitlist group consisted of 25 female caregivers and 7 male caregivers along with 27 male adolescents and 5 female adolescents. Data analyses were conducted using SPSS statistics, version 19 (IBM 2010). Statistical analyses suggested no significant differences on key demographic variables between parents who completed parenting measures and families who did not complete the intervention, those with missing or incomplete data, or families in which a different parent completed preand post-measures. Primary analyses were also conducted with male caregivers removed from both groups, with no major differences emerging in the outcomes reported in this paper. Parents in the final sample ranged from 32 to 56 years of age with an average of 46.3 years of age; teens ranged from 11 to 16 years of age with an average of 13.8 years of age at the time of intake. There were no significant differences on parent age or teen age between the experimental and waitlist groups. In addition, no significant differences between groups were found for teen intellectual functioning (as measured on the KBIT-2) or ASD symptom severity (as measured on the ADOS-G, Module 4). For additional demographic information, please see Tables 2 and 3.

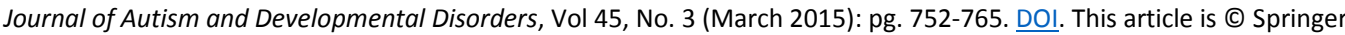
and permission has been granted for this version to appear in e-Publications@Marquette. Springer does not grant permission for this article to be further copied/distributed or hosted elsewhere without the express permission from Springer. 
NOT THE PUBLISHED VERSION; this is the author's final, peer-reviewed manuscript. The published version may be accessed by following the link in the citation at the bottom of the page.

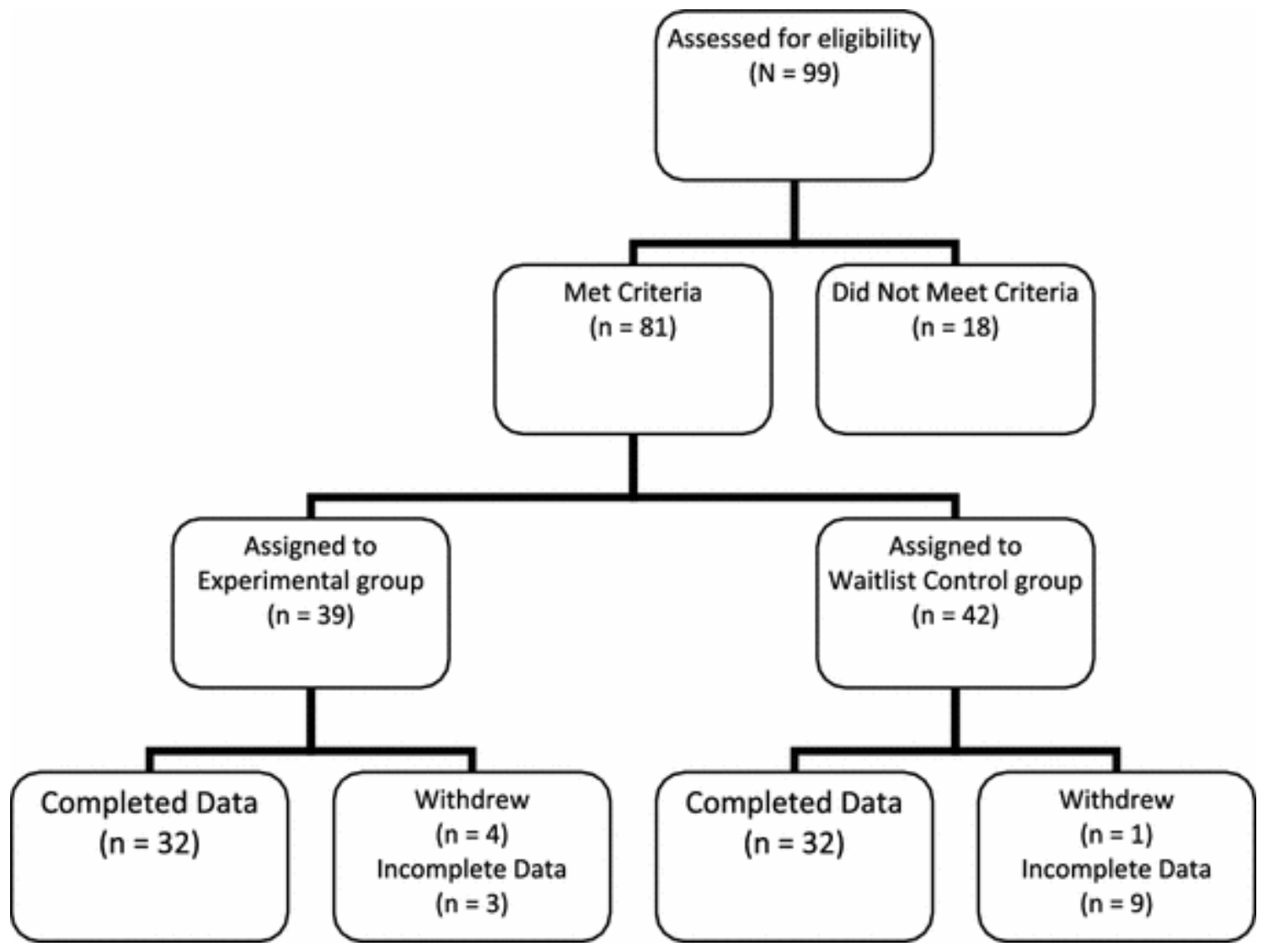

Fig. 1. PEERS recruitment CONSORT

Table 2. Demographic means and standard deviations

$\operatorname{EXP}(n=32)$

Parent age

Child age

\# of Siblings

Verbal SS

Non-verbal SS

Full scale IQ

ADOS communication

ADOS social interaction

ADOS total score

Vineland
$46.1(4.6)$

$14.1(1.3)$

$1.3(1.0)$

100.65 (18.75)

$102.00(18.38)$

$101.94(18.32)$

$3.91(1.60)$

$7.38(2.03)$

11.34 (3.19)

$75.13(11.21)$

WL $(n=32)$

$46.6(5.6)$

$13.4(1.5)$

$1.5(0.9)$

$95.60(18.29)$

101.56 (15.85)

$98.63(18.00)$

$3.56(1.52)$

$7.66(2.32)$

11.12 (3.42)

$78.82(12.84)$

EXP experimental group, WL waitlist control group, SS standard score, Vineland vineland total adaptive behavior composite 
NOT THE PUBLISHED VERSION; this is the author's final, peer-reviewed manuscript. The published version may be accessed by following the link in the citation at the bottom of the page.

Table 3. Demographic frequency statistics

\begin{tabular}{|c|c|c|c|}
\hline $\begin{array}{l}\text { Marital status } \\
\text { EXP }\end{array}$ & Education level & Income & Parent race/ethnicity \\
\hline Married $=24$ & High school $=1$ & Under $25 \mathrm{~K}=2$ & Black non-Hispanic $=1$ \\
\hline Divorced $=7$ & Some college $=6$ & $25-50 k=4$ & White non-Hispanic $=30$ \\
\hline Unmarried $=1$ & $\begin{array}{l}\text { College degree }=19 \\
\text { Advanced degree }=3\end{array}$ & $\begin{array}{l}50-75 k=7 \\
75-100 k=3 \\
100 k+=15\end{array}$ & White Hispanic $=1$ \\
\hline WL & & & \\
\hline Married $=25$ & High school $=3$ & Under $25 \mathrm{k}=1$ & Black non-Hispanic $=2$ \\
\hline Divorced $=4$ & Some college $=2$ & $25-50 k=5$ & White non-Hispanic $=29$ \\
\hline Separated $=1$ & College degree $=19$ & $\begin{array}{l}50-75 k=4 \\
75-100 k=5\end{array}$ & White Hispanic $=1$ \\
\hline Unmarried $=2$ & Advanced degree $=8$ & $100 \mathrm{k}+=15$ & \\
\hline
\end{tabular}

\section{Procedure}

\section{Recruitment}

Families were recruited for participation in PEERS through local ASD support, service, and diagnostic agencies, advertisements in the local Autism Society newsletter, and through word of mouth from families with previous participation. Upon calling to express interest in PEERS, families were provided with a brief synopsis of the program and, if interested, participated in a telephone screening process to ensure that teens met criteria for initial inclusion in PEERS. This screener is included in the PEERS manual and provided a brief assessment of teen interest in the program and intellectual functioning as well as family willingness to participate in treatment. At this point, all families meeting criteria for potential enrollment were placed on a call list for the next available round of intake appointments, which were held twice annually in August and January. A maximum number of 20 children were accepted for each round of intakes, allowing for a maximum of 10 adolescents in each intervention group, the highest number recommended for PEERS groups by Laugeson and Frankel (2010) 
NOT THE PUBLISHED VERSION; this is the author's final, peer-reviewed manuscript. The published version may be accessed by following the link in the citation at the bottom of the page.

\section{Randomization and Inclusion Criteria}

Following initial enrollment in PEERS via the phone screener, families were randomly assigned to either the "experimental" or "control" group (see Fig. 1 for CONSORT diagram detailing process of enrollment). Random assignment was completed for each set of intakes, which comprised of between 14 and 20 families each (i.e., 710 adolescents per group), and was done by alternating assignment per subject number. The only contingency to random assignment was that no PEERS group could contain only one child of either gender. Inclusion for enrollment in PEERS and this study included meeting several criteria. First, the adolescent had to clearly state interest in participating in the group via administration of a PEERS-specific mental status checklist (Laugeson and Frankel 2010). Second, the teen and his or her parent(s) needed to be willing to attend PEERS regularly, with a maximum of two absences allowed. In addition, the child needed to obtain a verbal and full scale IQ score on the Kaufman Brief Intelligence Test-Second Edition (Kaufman and Kaufman 2004) of greater than or equal to 70 . Further, teens needed to be between the ages of 11 and 16 years old at the time of their intake, and be enrolled in either middle school or high school. Finally, the child had to meet criteria for a diagnosis of either Autism or Autism Spectrum Disorder on the Autism Diagnostic Observation Schedule-General (ADOS-G; Lord et al. 2002), Module 4. The ADOS-G is a gold standard of ASD evaluation (Ozonoff et al. 2005), and trained members of the PEERS team who had established ADOS coding reliability completed administration of the ADOS-G. Of note, given that this study was commenced prior the publication of the DSM-5, it is not clear whether all participants would meet new criteria for an ASD diagnosis given the required presence of restricted or repetitive interest and behaviors. An additional requirement was that teens not have comorbid severe mental health disorders (e.g., psychotic disorders). However, no potential participants were excluded due to this criterion.

\section{Pre-assessment}

Prior to the first intake appointment, the parent or parents who planned on attending PEERS sessions were asked to attend this appointment with their teen. For both groups, the intake process consisted of the following: First, parent consent and teen assent for 
participation in PEERS and the research associated with PEERS were reviewed and signed. Next, in a separate room from their teen, parents completed questionnaires for this study as well as measures pertaining to their child's social skills, emotional and adaptive functioning, and behavior. Concurrently, teens were administered the ADOS-G and KBIT-2 to ensure that they met criteria for enrollment in PEERS. Parents were informed immediately regarding their teen's eligibility for participation. The teens were then provided with a variety of questionnaires regarding their social skills, experiences, and selfperception. Following administration of these questionnaires, teens participated in other components of the broader investigation of PEERS. At the conclusion of the intake process, families were notified of their assignment to either the experimental or waitlist group to ensure that responses were not biased by group assignment.

\section{PEERS Intervention}

Following completion of the intake process, parents and teens in the Experimental group attended 14 weekly sessions of PEERS spaced out over a 16-week period to allow time for holiday and school breaks. Parent and teen sessions consisted of concurrent but separate, weekly, 90-min, didactic sessions that strictly adhered to the treatment outline in the PEERS manual (Laugeson and Frankel 2010).

The PEERS intervention focused on numerous important topics related to initiating and maintaining friendships in adolescence (see Table 1). Major themes presented to teens during PEERS included identifying appropriate friends, trading information and establishing common interests with others, improving conversational skills, hosting get-togethers with friends, and dealing with negative events such as teasing, bullying, and arguments. In addition to these topics, Laugeson et al. (2009) identified three core features of PEERS intervention. The first primary feature is the small group format of PEERS, which is recommended to include between 5 and 10 teenagers. Secondly, Laugeson et al. noted that parent involvement is crucial and allows for direct instruction of social skills, supervision and practice throughout intervention, and support of the child's attempts to develop appropriate friendship networks. Finally, the lessons presented in PEERS are founded on social etiquette rules consistent with modernday adolescent relationships. These skills are presented in concrete, 
directed lessons in accordance with the optimal learning style of children with ASD (Laugeson and Frankel 2010). Regular fidelity checks were conducted by trained undergraduate assistants to ensure treatment remained adherent to the PEERS manual and was equivalent between groups.

Teen PEERS sessions were led by Master's level students in the Clinical Psychology doctoral program, under the supervision of a certified PEERS provider who had participated in formal on-site training from the developers of the PEERS treatment manual. Teen group leaders were assisted by trained undergraduate psychology students, who acted as "coaches" during behavioral rehearsal of skills learned in PEERS and assisted in role-play presentations of rules. Parent sessions were led by advanced graduate students in the Clinical Psychology Doctoral Program, again under the supervision of the trained PEERS provider, who provided weekly hour-long supervision sessions for both graduate students and coaches.

The treatment sessions were held in two separate rooms within the Psychology Department's mental health clinic. The teen sessions followed a regular format beginning with homework review (e.g., discussion of each teen's get-together), followed by presentation of the new didactic lesson, therapist and coach "role play," behavioral rehearsal, review of new homework, and re-unification with parents (which includes a review of the lesson and homework assignment). Didactic lessons focused on presentation of social guidelines, which were written in numerical sequence on a whiteboard at the front of the room, while teens were asked to participate in discussion of why these rules helped build and maintain friendships. For example, the session on "handling disagreements" outlined a multi-step method for resolving conflict with friends, after which teens participated in a mock disagreement with the PEERS leader or coach in which they were asked follow these steps in sequence. Behavioral rehearsals were carried out through indoor or outdoor activity period to help generalize the skills learned in group, with therapist and coaches providing in vivo feedback. For example, following the lesson on good sportsmanship, teens were asked to play a game amongst a small group (2-3 other participants) while utilizing the rules they had just learned. The PEERS parent sessions included homework review and troubleshooting, discussion of that week's didactic lesson, and review of homework for 
the upcoming week prior to re-unification. Per the PEERS manual, parents were discouraged from using the meeting as a support group, but were free to provide instrumental support by offering advice for how they had overcome specific barriers to implementing lessons and completing PEERS homework. The final week of PEERS consisted of a graduation ceremony and party, where parents reviewed major concepts of the group and discussed plans for moving forward after PEERS, while teens were rewarded with prizes and games dependent on the level of individual and group participation.

During the treatment period, the waitlist control group was free to access community services and resources as needed. Parents were asked to report on the use of such services for themselves, their family, or their child at the time of their follow-up appointment with the administration of a brief survey.

\section{Post-assessment}

After the experimental group had completed the PEERS program, both the waitlist and experimental groups completed the same measures and procedures as during the intake session. The outtake sessions were mostly similar to the intake sessions; though consent and assent procedures and administration of the ADOS-G and KBIT-2 did not take place. Teens were again asked to complete their forms in a separate room from their caregiver and had a graduate or undergraduate research assistant available to answer questions about any items.

\section{Measures}

Confusion, Hubbub, and Order Scale (CHAOS)

The CHAOS (Matheny et al. 1995) is a 15-item, parent-report measure assessing environmental confusion in the home. Items are presented on a 6-point Likert scale from "Strongly Agree" to "Strongly Disagree," with higher scores indicating greater reported family chaos. Examples of items include "Your family almost always seems to be rushed" and "The atmosphere in your home is calm." Matheny et al. (1995) reported good internal consistency (0.79) among items. Further, Coldwell et al. (2006) confirmed significant bivariate 
correlations between household chaos, as measured by the CHAOS, and parenting factors such as warmth, enjoyment, anger, hostility, and parent-child positivity and negativity. Additionally, Coldwell et al. found that household chaos, as measured by the CHAOS, predicted problem behavior in children over and above parenting factors, suggesting strong construct validity of the CHAOS. Assessment of scale reliability via Cronbach's alpha suggested good internal consistency (.87 and .81) at pre and post intervention in this study.

\section{Stress Index for Parents of Adolescents (SIPA)}

The SIPA (Sheras et al. 1998) is a screening and diagnostic instrument that identifies areas of stress in parent-adolescent interactions and is appropriate for parents of adolescents ranging in age from 11 to 19 years. The SIPA consists of 90 items assessing the amount of stress experienced by a parent as a function of specific characteristics of his/her adolescent life (i.e. Adolescent Domain), functioning that relates to a parent's distress as he/she interacts with the adolescent (i.e. Parent Domain), and the perceived quality of the relationship that the parent has with the adolescent (i.e., AdolescentParent Relationship Domain). These scales combine to form a Total Parenting Stress score. There is also a 22-item scale that measures the number of stressful life events the parent has experienced in the past year. The majority of subscale coefficient alphas range from the high $.80 \mathrm{~s}$ to .90 , and test-retest reliability estimates for a 4-week interval range from .74 to .93 for SIPA subscales (Sheras et al. 1998). Parenting stress as assessed by the SIPA has been found to relate to the quality of parents' perceptions of their parenting alliance, other psychological measures of adolescent and parent functioning, and the quality of the marital relationship and family system (Sheras et al. 1998). Ozonoff et al. (2005) identified the SIPA as a psychometrically sound measure for use with parents of adolescents with ASD. Within this study, Cronbach's alpha suggested strong internal consistency (.95) at pre and post intervention.

\section{Parenting Sense of Competence Scale (PSOC)}

The Parenting Efficacy subscale of the PSOC (Gibaud-Wallston and Wandersman 1978, as cited in Johnston and Mash 1989) is a 7item, parent-report measure of parenting self-efficacy, defined as the 
"degree to which the parent feels competent, capable of problem solving, and familiar with parenting (Johnston and Mash 1989, p. 173) The measure includes a six-point Likert-scale ranging from "Strongly Disagree" (6) to Strongly Agree (1) on statements such as "I meet my own personal expectations for expertise in caring for my child" and "If anyone can find the answer to what is troubling my child, I am the one"(Johnston and Mash 1989, p. 171). Reverse scoring is used such that higher scores indicate greater levels of parenting self-efficacy. Johnston and Mash (1989) reported good internal consistency within the parenting efficacy subscale (alpha $=0.76$ ) and as well as good divergent construct validity from the other subscale of the PSOC (Parenting Satisfaction). Cronbach's alpha suggested excellent internal consistency at pre (.90) and post (.92) intervention for this study.

\section{Results}

\section{Exploratory Analyses}

Exploratory bivariate correlational analyses were conducted to assess for linear relationships among variables of interest for the total sample. This allowed for better understanding of the overlap among parent and family constructs as well as determination of whether child factors such as cognitive ability and ASD symptomology were related to parent and family functioning. (See Table 4 for summary). When assessing parent report across both groups, Pearson's $r$ correlations suggested a significant inverse relationship between parenting selfefficacy (PSOC) and total parenting stress (SIPA), $r(62)=-.47$, $p<.001$, as well as between parenting self-efficacy and family chaos (CHAOS), $r(62)=-.50, p<.001$. Parenting stress and family chaos were also inversely related, $r(62)=.30, p=.017$. None of the primary variables of interest were significantly correlated with full scale IQ on the KBIT-2 or total score on the ADOS-G.

Table 4. Significant bivariate correlations among variables of interest prior to intervention $(n=64)$

\section{SIPA-TS}

PSE (PSOC)

Parent age

Teen age

\begin{tabular}{ll}
\multicolumn{1}{c}{ SIPA-TS } & \multicolumn{1}{c}{ PSE (PSOC) } \\
- & $-.474 * *$ \\
- & - \\
-.108 & -.078 \\
-.017 & -.125
\end{tabular}

\section{CHAOS}

$.298 *$

$-.502 * *$

$-.092$

.062

Journal of Autism and Developmental Disorders, Vol 45, No. 3 (March 2015): pg. 752-765. DOI. This article is (C) Springer and permission has been granted for this version to appear in e-Publications@Marquette. Springer does not grant permission for this article to be further copied/distributed or hosted elsewhere without the express permission from Springer. 
NOT THE PUBLISHED VERSION; this is the author's final, peer-reviewed manuscript. The published version may be accessed by following the link in the citation at the bottom of the page.

\begin{tabular}{llcl} 
& \multicolumn{1}{c}{ SIPA-TS } & PSE (PSOC) & \multicolumn{1}{c}{ CHAOS } \\
\# of siblings & -.009 & -.002 & -.002 \\
FSIQ (KBIT-2) & .099 & -.081 & .047 \\
ADOS-G total score & .152 & -.097 & .033 \\
$* p<.05$ & & \\
$* * p<.01$ & & \\
SIPA-TS stress index for parents of adolescents-total parenting stress, PSE parenting \\
self-efficacy, PSOC parenting sense of competence scale, CHAOS confusion, hubbub, \\
$\begin{array}{l}\text { and order scale, KBIT-2 kaufman brief intelligence test, second edition, ADOS Autism } \\
\text { diagnostic observation schedule, general }\end{array}$
\end{tabular}

\section{Primary Analyses}

To assess hypotheses regarding significant change in the experimental group versus the waitlist control group from pre to postintervention, five mixed between-within subjects analysis of variance (ANOVA) were conducted (see Table 5 for scale means and standard deviations and Table 6 for ANOVA results).

Table 5. Scale means and standard deviations

\begin{tabular}{|c|c|c|c|c|}
\hline & EXP-pre & EXP-post & WL-pre & WL-post \\
\hline CHAOS-total score* & $40.4(11.7)$ & $38.7(9.1)$ & $36.9(10.7)$ & $39.6(14.5)$ \\
\hline SIPA-total stress T-score & $\begin{array}{l}211.7 \\
(32.4)\end{array}$ & $\begin{array}{l}200.4 \\
(35.3)\end{array}$ & $\begin{array}{l}215.4 \\
(50.4)\end{array}$ & $\begin{array}{l}218.8 \\
(49.9)\end{array}$ \\
\hline $\begin{array}{l}\text { PSOC-parenting self-efficacy } \\
\text { (mean) }\end{array}$ & $4.05(.78)$ & $4.29(.72)$ & $4.46(.83)$ & $4.43(.66)$ \\
\hline $\begin{array}{l}\text { Significant interaction effect } \\
X P \text { experimental group, } W L \\
\text { rder scale, SIPA stress index } \\
\text { ompetence scale }\end{array}$ & $\times$ time & $<.05$ & & \\
\hline
\end{tabular}

Table 6. Mixed between-within subjects ANOVAS

\section{Scale}

CHAOS (Confusion, hubbub, and order scale)

$\begin{array}{lllll}\text { Main effect: time (within subjects) } & 1,62 & 0.18 & .00 & .67 \\ \text { Main effect: group (between subjects) } & 1,62 & .22 & .00 & .64 \\ \text { Interaction: time } \times \text { group } & 1,62 & 4.26 & .06 & .04 \\ \text { SIPA: total stress } & & & & \\ \text { Main effect: time (within subjects) } & 1,62 & 0.60 & .01 & .44 \\ \text { Main effect: group (between subjects) } & 1,62 & 1.44 & .02 & .20 \\ \text { Interaction: time } \times \text { group } & 1,62 & 1.63 & .03 & .23 \\ \text { PSOC: parenting self-efficacy } & & & & \\ \text { Main effect: time (within subjects) } & 1,62 & 0.91 & .01 & .34 \\ \text { Main effect: group (between subjects) } & 1,62 & 3.12 & .05 & .08 \\ \text { Interaction: time } \times \text { group } & 1,62 & 1.44 & .02 & .23\end{array}$

Journal of Autism and Developmental Disorders, Vol 45, No. 3 (March 2015): pg. 752-765. DOI. This article is (C) Springer and permission has been granted for this version to appear in e-Publications@Marquette. Springer does not grant permission for this article to be further copied/distributed or hosted elsewhere without the express permission from Springer. 
NOT THE PUBLISHED VERSION; this is the author's final, peer-reviewed manuscript. The published version may be accessed by following the link in the citation at the bottom of the page.

SIPA stress index for parents of adolescents, PSOC parenting sense of competence scale

\section{Family Chaos}

In assessing overall family disruption from the CHAOS, there was not a significant main effect for time or group. However, there was a significant interaction effect between time and group, Wilks Lambda $=.936, F(1,62)=4.26, p=.04$, partial eta squared $=.06$, suggesting a significant difference between groups over time in the domain of family disruption and distress, with the experimental group showing a significant decrease in family chaos over time in comparison to the waitlist control group (see Fig. 2). Follow-up of this interaction via simple effects paired $t$ tests suggested marginally significant reduction in family chaos in the experimental group $(p=.07)$, with a non-significant increase in the waitlist control group $(p=.18)$.

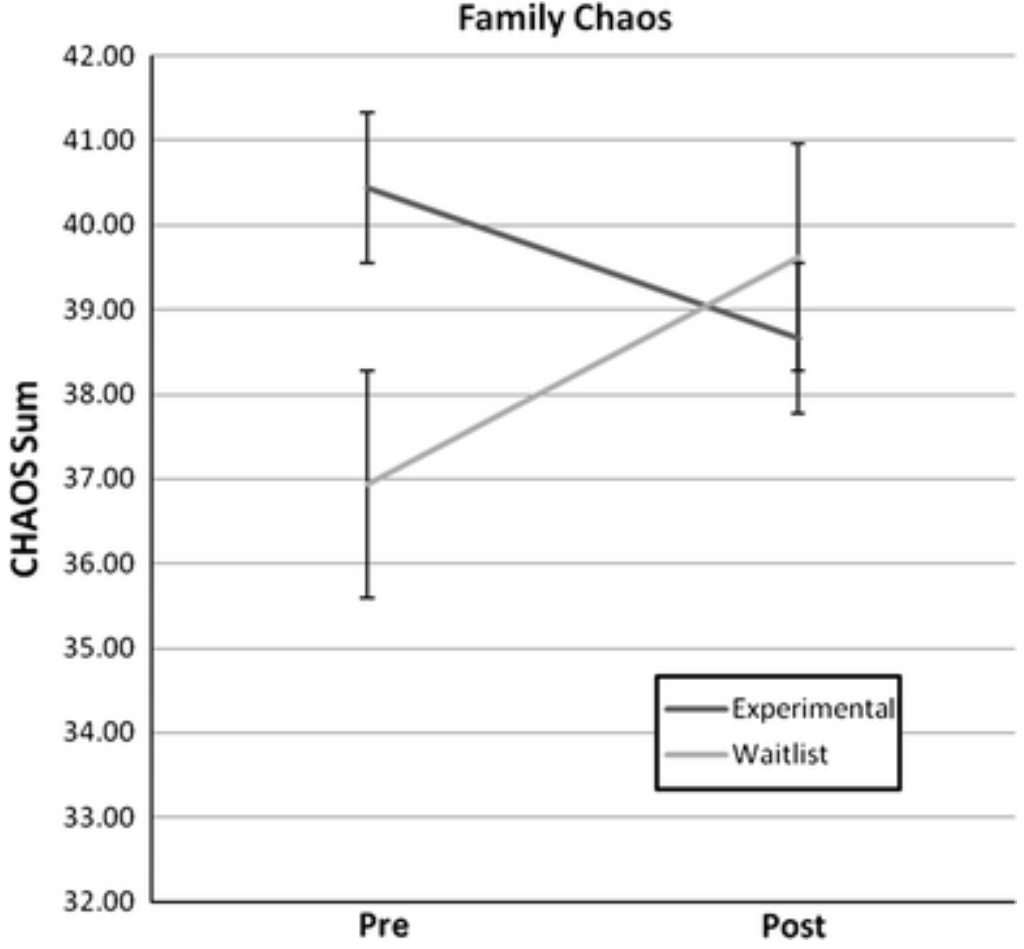

Fig. 2. Total family chaos scores on the confusion, hubbub, and order scale (CHAOS). Error bars represent standard error $( \pm 1 \mathrm{SE})$ 
NOT THE PUBLISHED VERSION; this is the author's final, peer-reviewed manuscript. The published version may be accessed by following the link in the citation at the bottom of the page.

\section{Parenting Stress}

In assessing the impact of PEERS on total parenting stress Tscores from the SIPA, there was not a significant main effect for time or group. There also was not a significant interaction effect between time and group $(p=.23$, partial eta squared $=.03)$, suggesting no significant difference between groups over time in total parenting stress (see Fig. 3).

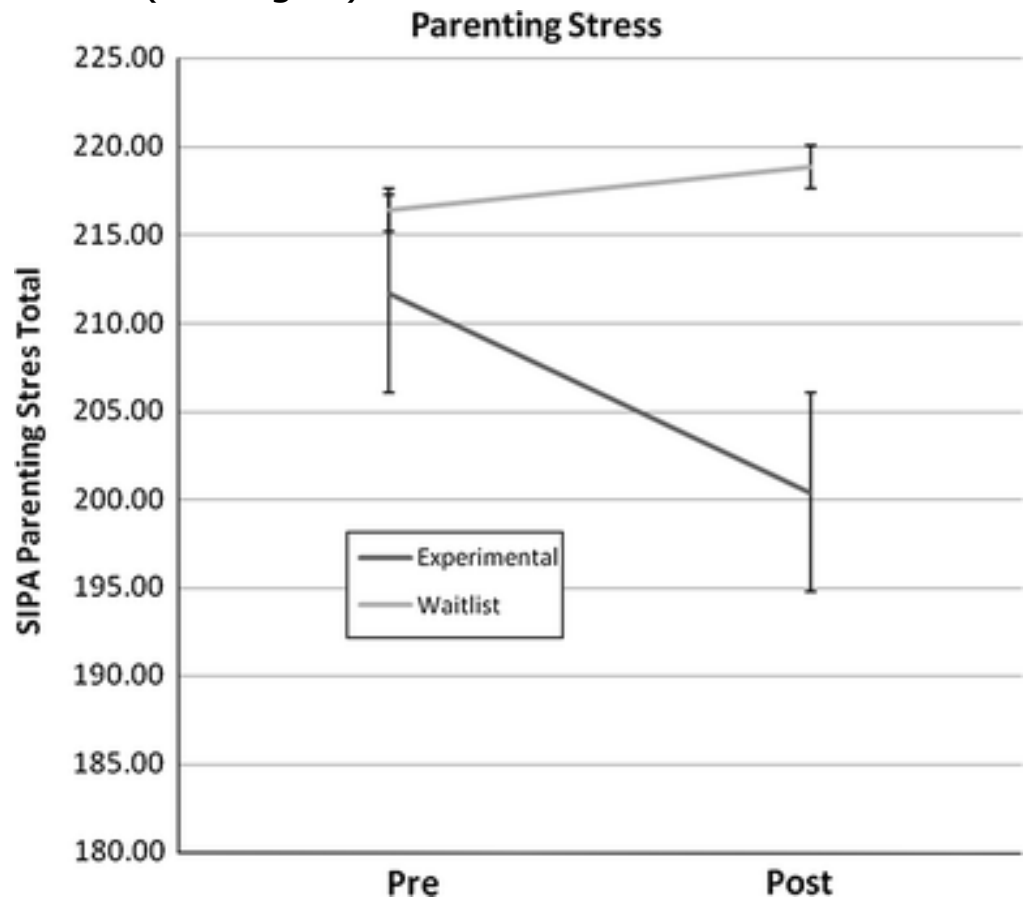

Fig. 3. Total parenting stress scores on the stress index for parents of adolescents (SIPA). Error bars represent standard error ( $\pm 1 \mathrm{SE})$

\section{Parenting Self-Efficacy}

There was not a significant main effect for time or group when evaluating parenting self-efficacy from the PSOC. Additionally, there was not a significant interaction between time and group $(p=.23$, partial eta squared $=.02$ ), suggesting no significant difference between groups over time in the domain of parenting self-efficacy (see Fig. 4). However, a planned analysis, via paired samples $t$ test, revealed a significant increase in parenting self-efficacy in the experimental group, $t(32)=2.18, p=.04$, from pre- to postintervention. 
NOT THE PUBLISHED VERSION; this is the author's final, peer-reviewed manuscript. The published version may be accessed by following the link in the citation at the bottom of the page.

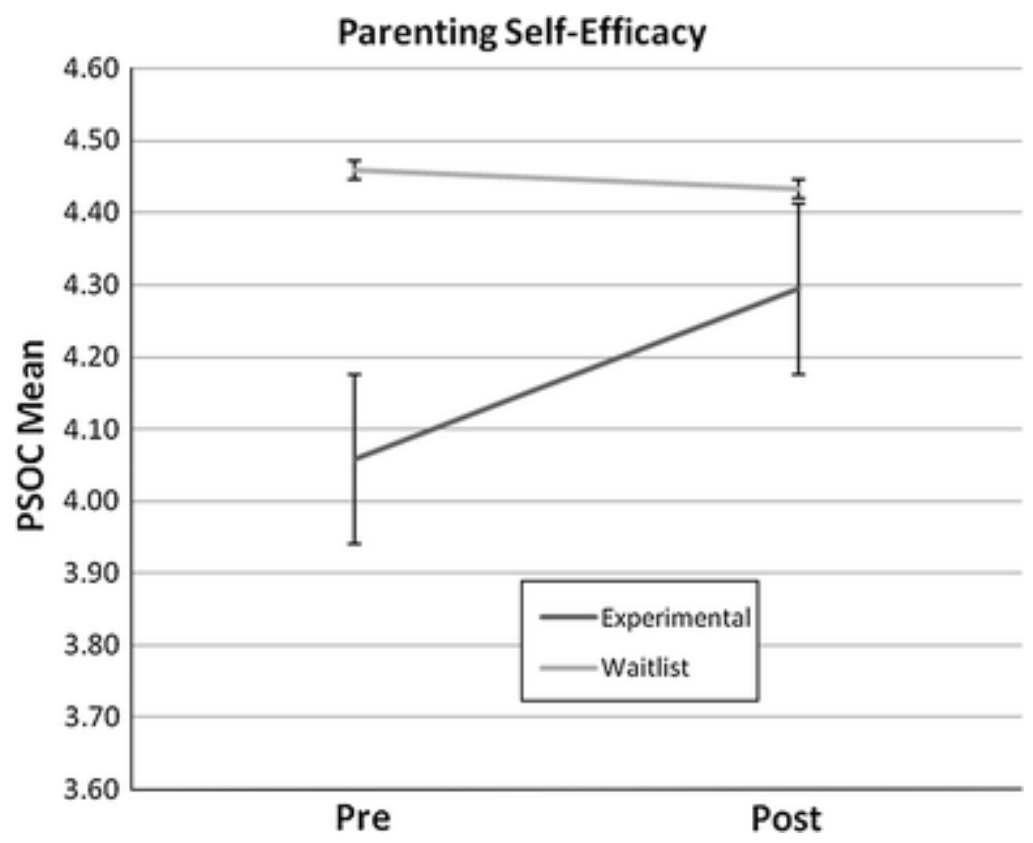

Fig. 4. Mean parenting self-efficacy scores from the parenting sense of competence scale (PSOC). Error bars represent standard error ( $\pm 1 \mathrm{SE})$

\section{Discussion}

There is a substantial body of research suggesting that raising a child with ASD is associated with elevated levels of family chaos and distress, increased parenting stress, and decreased parenting selfefficacy. Comprehensive interventions for ASD should address these larger issues, as systemic environmental changes appear necessary to ensure maintenance of treatment gains and improve long-term outcomes of therapy. However, family outcomes of ASD intervention are rarely assessed. This study assessed 64 families of adolescents with high-functioning ASD to determine whether involvement in the PEERS program would facilitate decreased family chaos, decreased parenting stress, and increased parenting efficacy.

\section{Conclusions}

Findings with regard to the primary hypotheses were mixed. There was a significant time $\times$ group interaction effect found for family chaos (as measured on the CHAOS), with the experimental group showing a non-statistically significant decrease in family chaos while the waitlist control group demonstrated an increase in chaos, though

Journal of Autism and Developmental Disorders, Vol 45, No. 3 (March 2015): pg. 752-765. DOI. This article is (C) Springer and permission has been granted for this version to appear in e-Publications@Marquette. Springer does not grant permission for this article to be further copied/distributed or hosted elsewhere without the express permission from Springer. 
this main effect was also not significant. The difference in change within the domain of family chaos demonstrated a medium effect size (Cohen 1988; eta squared $=.064$ ). Though the individual group changes were not statistically significant, taken together it appears that family involvement in PEERS may have a positive impact on structure and order in the home.

The significant interaction found on the CHAOS measure reflects an important, and in some ways counterintuitive, potential benefit of PEERS intervention. Throughout the program, families are asked to take on numerous "homework" tasks, including making both in-group and out-of-group phone calls and hosting get-togethers with sameaged peers. The additional time burden necessitated by completing these tasks each week (in addition to attending PEERS for 90 min each week) is a necessary component of the intervention process that could potentially increase family disruption. The fact that these requirements did not increase chaos, and thus did not mitigate the systemic benefits of improved adolescent socialization, is extremely encouraging and suggests that these families may have found these tasks meaningful and beneficial despite the extra time and effort required. Instead, it is possible that the homework assignments had an "organizational effect" on families, making it necessary to integrate more structure and routine into the home and therefore reducing chaos. In addition, it is notable that the CHAOS measure specifically attempts to quantify environmental confusion, and it is possible that the provision of "rules" within the PEERS treatment curriculum provides families with more structure and order for managing social interactions. Finally, it is possible that direct benefits of PEERS on the adolescent participants (e.g., increased get-togethers) allowed for a more developmentally normative amount of "social time" for teens, opening up availability for parents to regain order and establish a more regular routine in the home.

When assessing parenting stress via the SIPA, we could not reject the null hypothesis that parents participating in PEERS experienced a decrease in parenting stress that was significant over and above that of a waitlist control group. Large variance in the overall sample and a small effect size appeared to contribute to a lack of statistical significance when assessing the time (pre to post intervention $) \times$ group (experimental vs. waitlist control) interaction. 
Nonetheless, the direction of the effect seen was in the hypothesized direction and suggests that the effect of participation in PEERS on parenting stress warrants further evaluation with an increased sample size and/or use of a more sensitive measure (perhaps an ASD-focused instrument).

With respect to parenting self-efficacy, there was an increase in mean parenting self-efficacy (as measured on the PSOC) in the experimental group, while the waitlist group's mean self-efficacy score remained essentially unchanged. Paired sample $t$ test analysis suggested that the increase in parenting self-efficacy from pre to posttreatment in the experimental group was statistically significant at $p<.05$. However, mixed between-within ANOVA analysis suggested that the time $\times$ group interaction effect was not statistically significant. Thus, while there did appear to be a statistically significant increase in parenting self-efficacy for the experimental group following PEERS intervention, this change was not significant over and above a nointervention waitlist control group. It is believed that the increased variance in the waitlist group contributed at least somewhat to the lack of a statistically significant finding in this domain. This finding warrants further investigation with an increased sample size, and it is encouraging that participation in PEERS did appear to increase parenting self-efficacy. Further research in this domain appears important given the mediating effect established for parenting selfefficacy between child behavior problems and maternal mental health (Hastings and Brown 2002).

Analysis of linear relationships among the entire sample $(n=64)$ prior to intervention also revealed very interesting and meaningful associations among variables of interest that should be considered when understanding and evaluating parent outcomes of treatment. Replicating a finding by Giallo et al. (2011), parenting selfefficacy was negatively associated with parenting stress, suggesting that parents who feel less confidence in their abilities feel more overwhelmed by the many demands of raising a child with an ASD. In addition, there was an inverse correlation between parenting selfefficacy and family chaos, a relationship that warrants further analysis. It is possible that parents with less confidence in their own abilities provide less structure and order for the family, or conversely that a chaotic household leaves parents feeling less in control and thus less 
efficacious. In addition, it is notable that neither adolescent intellectual functioning (as measured by scores on the KBIT-2) nor ASD symptomology (as measured by total score on the ADOS-G) were associated with parenting stress, parenting self-efficacy, or family chaos. This finding replicates earlier research which demonstrated no difference in parenting stress for parents of children with or without cognitive deficits (Davis and Carter 2008; Rao and Beidel 2009) or for parents of children with varying severity of social and communicative impairment (Tomanik et al. 2004). The fact that parenting stress and self-efficacy do not appear related to these domains of child functioning highlights the need for parent involvement in treatment even when teens are classified as "higher-functioning," as was the case in the present study.

\section{Implications}

Overall, results from this study suggest that the PEERS intervention offers promising adjunctive benefits for families in addition to the improved teen social outcomes resulting from PEERS demonstrated in the larger project encompassing this study as well as those conducted by others research groups (e.g., Laugeson et al. 2011; Mandelberg et al. 2014; Schohl et al. 2014). The significant time $\times$ group interaction found on the CHAOS highlights the way in which the PEERS intervention, through the use of concurrent parent and teen sessions, may help improve the trajectory of family chaos or dysfunction for families heavily burdened by their child's diagnosis and associated impairments. Changes made during the intervention could very well improve the home environment post-treatment, making this setting more conducive to social gatherings, decreasing family disruption that often impedes social opportunities, and helping eliminate conflict that exacerbates ASD symptomology (Kelly et al. 2008). In addition, the fact that parenting self-efficacy showed a statistically significant increase following PEERS intervention (though this was not significant over and above the waitlist control group) appears very important given the relationship between parenting selfefficacy and child behavior problems (Sofronoff and Farbotko 2002). 
NOT THE PUBLISHED VERSION; this is the author's final, peer-reviewed manuscript. The published version may be accessed by following the link in the citation at the bottom of the page.

\section{Limitations and Future Directions}

There are several notable limitations to the present study. Perhaps the most significant limitation were small effect sizes found for the primary outcome variables, particularly with respect to parenting stress and parenting self-efficacy. An additional limitation was the lack of a control group which did not include direct parent and family involvement. Further, this study did not compare PEERS outcomes to those of another form of intervention as is no "gold standard" for social skills intervention, as no current format has yet to meet Chambless et al. (1996) criteria to be considered empirically validated.

An unavoidable limitation resulted from the fact that the control group was not restricted from participating in other available interventions. However, parent report suggested that adjunctive therapy for the waitlist control group was minimal (i.e., only a few participants with psychopharmacological intervention). Another limitation related to the control group is that at the time of intake, while parents did not know which group they would be assigned to, they did know that they would be enrolled in an intervention soon if their child met inclusion criteria. While a brief waiting period was not preferable compared to immediate enrollment, the paucity of therapies available for adolescents with ASD also means that even parents in the control group may have experienced increased hopefulness. Thus, the promise of an empirically supported (and no-cost) intervention was essentially made to all participants meeting inclusion criteria, which may have altered parent report prior to intervention across groups. In addition, the fact that our intervention was offered free of charge to families (in exchange for their research participation) eliminated a common stressor associated with therapy for families.

The use of parent-report measures in this study is an additional limitation, as social desirability could introduce bias in the results obtained. More objective measures (e.g., observational data) could be used in future studies to help reduce this bias. Further, to ensure independence of data, only one parent report per teen was obtained for this study. Future research should also gather information regarding the functioning and well-being of other parents or family members in order to obtain a more robust understanding of the 
systemic environment. This study was also limited by the lack of data collection during PEERS, such as at a mid-point during the intervention, which would have allowed for assessment of non-linear patterns related to the variables of interest. PEERS intervention requires weekly homework assignments which include having adolescents enroll in one or two extracurricular activities, call friends from social groups at school or in the community, and having parents and teens to facilitate regular "get-togethers." These activities are often stressful for parents and anxiety provoking for teens, as they often necessitate approaching difficult tasks that have long been avoided. Anecdotally, many parents acknowledged an initial increase in both their own stress early in the intervention, followed by a decrease in distress as the teens begin developing meaningful relationships. A more regular assessment of teen and parent functioning would help identify if this was actually the case for most participants. If this pattern does occur, it is possible that parenting stress continues to decrease after intervention. Future studies should include long-term collection of both parent and teen data, which would allow for analysis of maintenance of treatment gains.

It also should be noted that our sample was relatively homogenous, consisting primarily of Caucasian families. Though PEERS intervention for this study was offered free of charge, the majority of the parents were also well-educated and reported relatively high incomes. It is hoped that future studies will include families from more diverse racial, ethnic, cultural, and socioeconomic backgrounds. Further, because inclusion criteria included meeting a minimum IQ composite score on the KBIT-2, our sample consisted only of "highfunctioning" adolescents with ASD. Thus, our sample may not generalize to the greater ASD population.

\section{Summary}

This study extends the research base regarding PEERS intervention and suggests that the benefits of PEERS extend beyond the adolescent to the entire family system. Data also suggest that parents benefit from PEERS through increased confidence in their own parenting abilities. 
NOT THE PUBLISHED VERSION; this is the author's final, peer-reviewed manuscript. The published version may be accessed by following the link in the citation at the bottom of the page.

\section{Acknowledgments}

This research was part of a doctoral dissertation and was supported by grants from the Organization for Autism Research (OAR) as well as the Marquette University Forward Thinking Program. Collaboration and guidance for implementation of PEERS was provided by Dr. Elizabeth Laugeson at the University of California, Los Angeles.

\section{References}

American Psychiatric Association. (2013). Diagnostic and statistical manual of mental disorders: fifth edition (DSM-5). Washington, DC: American Psychiatric Association.

Brobst, J. B., Clopton, J. R., \& Hedrick, S. S. (2009). Parenting children with Autism Spectrum Disorders: The couple's relationship. Focus on Autism and Other Developmental Disabilities, 24(1), 38-49. doi: $10.1177 / 1088357608322699$. CrossRef

Center for Disease Control and Prevention. (2014, March 28). Autism Spectrum Disorder (ASD) Data and Statistics. Centers for Disease Control and Prevention. Retrieved April 10, 2014, from http://www.cdc.gov/ncbddd/autism/data.html.

Chambless, D. L., Sanderson, W. C., Shoham, V., Johnson, S. B., Pope, K. S., Crits-Christoph, P., et al. (1996). An update on empirically validated therapies. The Clinical Psychologist, 49, 518.

Cohen, J. (1988). Statistical power analysis for the behavioral sciences (2nd ed.). New Jersey: Lawrence Erlbaum.

Coldwell, J., Pike, A., \& Dunn, J. (2006). Household chaos: Links with parenting and child behavior. Journal of Child Psychology and Psychiatry, 47(11), 1116-1122. doi:10.1111/j14697610.2006.01655.x.

Davis, N. O., \& Carter, A. S. (2008). Parenting stress in mothers and fathers of toddlers with autism spectrum disorders: Associations with child characteristics. Journal of Autism and Developmental Disorders, 38(7), 1278-1291. doi:10.1007/s10803-007-0512-z.

Duarte, C. S., Bordin, I. A., Yazigi, L., \& Mooney, J. (2005). Factors associated with stress in mothers of children with autism. Autism, 9(4), 416-427. doi:10.1177/1362361305056081. 
Ekas, N. V., Lickenbrock, D. M., \& Whitman, T. L. (2010). Optimism, social support, and well-being in mothers of children with Autism Spectrum Disorder. Journal of Autism and Developmental Disorders, 40, 1274-1284.

Estes, A., Munson, J., Dawson, G., Koehler, E., Zhou, X., \& Abbott, R. (2009). Parenting stress and psychological functioning among mothers of preschool children with autism and developmental delay. Autism, 13(4), 375-387.

doi:10.1177/1362361309105658.

Estes, A., Olson, E., Sullivan, K., Greenson, J., Winter, J., Dawson, G., \& Munson, J. (2012). Parenting-related stress and psychological distress in mothers of toddlers with Autism Spectrum Disorders. Brain \& Development, 1-6. doi:10.1016/j.braindev.2012.10.004.

Frankel, F., \& Myatt, R. (2003). Children's friendship training. New York: Brunner-Routledge.

Gau, S. S., Chou, M., Chiang, H., Lee, J., Wong, C., Chou, W., \& Wu, Y. (2011). Parental adjustment, marital relationship, and family function in families of children with autism. Research in Autism Spectrum Disorders, 1-8. doi:10.1016/j.rasd.2011.05.007.

Giallo, R., Wood, C. E., Jellett, R., \& Porter, R. (2011). Fatigue, wellbeing and parental self-efficacy in mothers of children with an Autism Spectrum Disorder. Autism, 1-16.

doi: $10.1177 / 1362361311416830$.

Harper, A., Dyches, T. T., Harper, J., Roper, S. O., \& South, M. (2013). Respite care, marital quality, and stress in parents of children with Autism Spectrum Disorders. Journal of Autism and Developmental Disorders, 43, 2604-2616. doi:10.1007/s10803013-1812-0.

Hartley, S. L., Barker, E. T., Seltzer, M. M., Greenberg, J. S., \& Floyd, F. J. (2011). Marital satisfaction and parenting experiences of mothers and fathers of adolescents and adults with autism. American Association on Intellectual and Developmental Disabilities, 116(1), 81-95. doi:10.1352/1944-7558-116.1.81. Hastings, R. P., \& Brown, T. (2002). Behavior problems of children with autism, parental self-efficacy, and mental health. American Journal on Mental Retardation, 107(3), 222. doi:10.1352/08958017(2002)1072.0.CO.2.

Journal of Autism and Developmental Disorders, Vol 45, No. 3 (March 2015): pg. 752-765. DOI. This article is @ Springer and permission has been granted for this version to appear in e-Publications@Marquette. Springer does not grant permission for this article to be further copied/distributed or hosted elsewhere without the express permission from Springer. 
Hayes, S. A., \& Watson, S. L. (2012). The impact of parenting stress: A meta-analysis of studies comparing the experience of parenting stress in parents of children with and without Autism Spectrum Disorder. Journal of Autism and Developmental Disorders, 1-14. doi:10.1007/s10803-012-1604-y.

Hoffman, C. D., Sweeney, D. P., Hodge, D., Lopez-Wagner, M. C., \& Looney, L. (2009). Parenting stress and closeness: Mothers of typically developing children and mothers of children with autism. Focus on Autism and Other Developmental Disabilities, 24(3), 178-187. doi:10.1177/1088357609338715.

Johnston, C., \& Mash, E. J. (1989). A measure of parenting satisfaction and efficacy. Journal of Clinical Child Psychology, 18(2), 167175. doi:10.1207/s15374424jccp1802_8.

Karst, J. S., \& Van Hecke, A. V. (2012). Parent and family impact of Autism Spectrum Disorders: A review and proposed model of intervention evaluation. Clinical Child and Family Psychology Review, 15(3), 247-277. doi:10.1007/s01567-012-0119-6.

Kaufman, A.S., \& Kaufman, N. L. (2004). KBIT-2: Kaufman brief intelligence test. Pearson.

Kelly, A. B., Garnett, M. S., Attwood, T., \& Peterson, C. (2008). Autism spectrum symptomatology in children: The impact of family and peer relationships. Journal of Abnormal Child Psychology, 36(7), 1069-1081. doi:10.1007/s10802-008-9234-8.

Lam, S., Wong, B. P., Leung, D., Ho, D., \& Au-Yeung, P. (2010). How parents perceive and feel about participation in community activities. Autism, 14(4), 359-377. doi: $10.1177 / 1362361309346558$.

Laugeson, E. A., \& Frankel, F. H. (2010). Social skills for teenagers with developmental and Autism Spectrum Disorders: The PEERS treatment manual. New York: Routledge.

Laugeson, E. A., Frankel, F., Gantman, A., Dillon, A. R., \& Mogil, C. (2011). Evidence-based social skills training for adolescents with Autism Spectrum Disorders: The UCLA PEERS program. Journal of Autism and Developmental Disorders, 1-12.

doi:10.1007/s10803-011-1339-1.

Laugeson, E. A., Frankel, F., Mogil, C., \& Dillon, A. R. (2009). Parentassisted social skills training to improve friendships in teens with Autism Spectrum Disorders. Journal of Autism and 
Developmental Disorders, 39(4), 596-606.

doi:10.1007/s10803-008-0664-5.

Laugeson, E. A., \& Park, M. N. (2014). Using a CBT approach to teach social skills to adolescents with Autism Spectrum Disorder and other social challenges: The PEERS method. Journal of RationalEmotive \& Cognitive-Behavioral Therapy, 32, 84-97. doi: 10.1007/s/10942-014-0181-8.

Lee, L., Harrington, R. A., Louie, B. B., \& Newschaffer, C. J. (2008). Children with autism: Quality of life and parental concerns. Journal of Autism and Developmental Disorders, 38, 11471160. doi: 10.1007/s10803-007-0491-0.

Lord, C., \& Bishop, S. L. (2010). Autism Spectrum Disorders: Diagnosis, prevalence, and services for children and families. Society for Research in Child Development, 24(2), 1-21.

Lord, C., Rutter, M., DiLavore, P. C., \& Risi, S. (2002). Autism diagnostic observation schedule: ADOS manual. Los Angeles, CA: Western Psychological Services.

Mandelberg, J., Laugeson, E. A., Cunningham, T. D., Ellingsen, R., Bates, S., \& Frankel, F. (2014). Long-term treatment outcomes for parent-assisted social skills training for adolescents with Autism Spectrum Disorders: The UCLA PEERS program. Journal of Mental Health Research in Intellectual Disabilities, 7, 45-73. Mandell, D. S., Xie, M., Morales, K., Lawer, L., McCarthy, M., \& Marcus, S. C. (2011). The interplay of outpatient services and psychiatric hospitalization among Medicaid-enrolled children with Autism Spectrum Disorders. Archives of Pediatric and Adolescent Medicine, 166(1), 68-73.

Matheny, A., Wachs, T., Ludwig, J., \& Phillips, K. (1995). Bringing order out of chaos: Psychometric characteristics of the confusion, hubbub, and order scale. Journal of Applied Developmental Psychology, 16(3), 429-444. doi:10.1016/01933973(95)90028-4.

McConachie, H., \& Diggle, T. (2007). Parent implemented early intervention for young children with autism spectrum disorder: A systematic review. Journal of Evaluation in Clinical Practice, 13(1), 120-129. doi:10.1111/j.1365-2753.2006.00674.x.

Midouhas, E., Yogaratnam, A., \& Charman, T. (2013). Psychopathology trajectories of children with Autism Spectrum Disorder: The role of family poverty and parenting. Journal of the American 
Academy of Child and Adolescent Psychiatry, 52(10), 10571065. doi: 10.1016/j.jaac.2013.07.011.

Morrison, J. Q., Sansosti, F. J., \& Hadley, W. M. (2009). Parent perceptions of the anticipated needs and expectations for support for their college-bound students with asperger's syndrome. Journal of Postsecondary Education and Disability, 22(2), 78-87.

Mugno, D., Ruta, L., D’Arrigo, V. G., \& Mazzone, L. (2007). Impairment in quality of life in parents of children and adolescents with pervasive developmental disorder. Health and Quality of Life Outcomes. doi:10.1186/1477-7525-5-22.

Osborne, L. A., McHugh, L., Saunders, J., \& Reed, P. (2008a).

Parenting stress reduces the effectiveness of early teaching interventions for autistic spectrum disorders. Journal of Autism and Developmental Disorders, 38(6), 1092-1103. doi:10.1007/s10803-007-0497-7.

Osborne, L., McHugh, L., Saunders, J., \& Reed, P. (2008b). The effect of parenting behaviors on subsequent child behavior problems in autistic spectrum conditions. Research in Autism Spectrum Disorders, 2(2), 249-263. doi:10.1016/j.rasd.2007.06.004. Ozonoff, S., Goodlin-Jones, B. L., \& Solomon, M. (2005). Evidencebased assessment of Autism Spectrum Disorders in children and adolescents. Journal of Clinical Child and Adolescent Psychiatry, 34(53), 523-540.

Pakenham, K. I., Samios, C., \& Sofrnoff, K. (2005). Adjustment in mothers of children with asperger syndrome: An application of the double ABCX model of family adjustment. Autism, 9(2), 191-212. doi:10.1177/1362361305049033.

Pottie, C. G., \& Ingram, K. M. (2008). Daily stress, coping, and wellbeing in parents of children with autism: A multilevel modeling approach. Journal of Family Psychology, 22(6), 855-864. doi:10.1037/a0013604.

Rao, P. A., \& Beidel, D. C. (2009). The impact of children with highfunctioning autism on parental stress, sibling adjustment, and family functioning. Behavior Modification, 33(4), 437-451. doi: $10.1177 / 0145445509336427$.

Rao, P. A., Beidel, D. C., \& Murray, M. J. (2008). Social skills interventions for children with Asperger's syndrome or highfunctioning autism: A review and recommendations. Journal of 
Autism and Developmental Disorders, 38(2), 353-361. doi:10.1007/s10803-007-0402-4.

Reichow, B., \& Volkmar, F. R. (2010). Social skills interventions for individuals with autism: Evaluation for evidence-based practices with a best evidence synthesis framework. Journal of Autism and Developmental Disorders, 40, 149-166. doi: 10.1007/s10803-009-0842-0.

Roberts, D., \& Pickering, N. (2010). Parent training programme for Autism Spectrum Disorders: An evaluation. Community Practitioner, 83(10), 27-30.

Rogers, S. J. (2000). Interventions that facilitate socialization in children with autism. Journal of Autism and Developmental Disorders, 30(5), 399-409.

Schertz, H. H., \& Odom, S. L. (2007). Promoting joint attention in toddlers with autism: A parent-mediated developmental model. Journal of Autism and Developmental Disorders, 37(8), 15621575. doi:10.1007/s10803-006-0290-z.

Schieve, L. A., Blumberg, S. J., Rice, C., Visser, S. N., \& Boyle, C. (2007). The relationship between autism and parenting stress. Pediatrics, 119(Supplement), S114-S121. doi:10.1542/peds.2006-2089Q.

Schieve, L. A., Boulet, S. L., Kogan, M. D., Yeargin-Allsopp, M., Boyle, C. A., Visser, S. N., et al. (2011). Parenting aggravation and Autism Spectrum Disorders: 2007 National survey of children's health. Disability and Health Journal, 4, 143-152. doi:10.1016/j.dhjo.2010.09.002.

Schohl, K., Van Hecke, A. V., Carson, A. M., Karst, J., \& Stevens, S. (2014). A replication and extension study of the PEERS relationship-development intervention with adolescents with Autism Spectrum Disorders. Journal of Autism and Developmental Disorders, 44, 532-545. doi:10.1007/s10803013-1900-1.

Sebastian, C., Blakemore, S., \& Charman, T. (2009). Reactions to ostracism in adolescents with autism spectrum conditions. Journal of Autism and Developmental Disorders, 39(8), 11221130. doi:10.1007/s10803-009-0725-4.

Sheras, P. L., Abidin, R. R., \& Konold, T. R. (1998). SIPA, stress index for parents of adolescents: Professional manual. Odessa, FL: Psychological Assessment Resources.

Journal of Autism and Developmental Disorders, Vol 45, No. 3 (March 2015): pg. 752-765. DOI. This article is (C) Springer and permission has been granted for this version to appear in e-Publications@Marquette. Springer does not grant permission for this article to be further copied/distributed or hosted elsewhere without the express permission from Springer. 
Siller, M., \& Sigman, M. (2002). The behaviors of parents of children with autism predict the subsequent development of their children's communication. Journal of Autism and Developmental Disorders, 32(2), 77-89.

Sivberg, B. (2002). Family system and coping behaviors: A comparison between parents of children with autistic spectrum disorders and parents with non-autistic children. Autism, 6(4), 397-409. doi:10.1177/1362361302006004006.

Sofronoff, K., \& Farbotko, M. (2002). The effectiveness of parent management training to increase self-efficacy in parents of children with asperger syndrome. Autism, 6(3), 271-286. doi: $10.1177 / 1362361302006003005$.

SPSS statistics 19.0 [Computer software]. (2010). IBM.

Tomanik, S., Harris, G., \& Hawkins, J. (2004). The relationship between behaviours exhibited by children with autism and maternal stress. Journal of Intellectual \& Developmental Disability, 29(1), 16-26. doi:10.1080/13668250410001662892. Volkmar, F. R., \& Pauls, D. (2003). Autism. The Lancet, 362, 11331141.

White, S., Keonig, K., \& Scahill, L. (2007). Social skills development in children with Autism Spectrum Disorders: A review of intervention research. Journal of Autism and Developmental Disorders, 37(10), 1858-1868. doi:10.1007/s10803-006-0320$x$.

Woodgate, R. L., Ateah, C., \& Secco, L. (2008). Living in a world of our own: The experience of parents who have a child with autism. Qualitative Heatlh Research, 18(8), 1075-1083. doi: $10.1177 / 1049732308320112$. 